\title{
Espacios Virtuales de Enseñanza y Aprendizaje (EVEA) en Esplacnología: Especificidades Pedagógicas en su Enseñanza Topográfica
}

\author{
Virtual Teaching and Learning Spaces (VTLS) in Splanchnology: Pedagogical Specificities in \\ Topographic Teaching
}

"Rubén Daniel Algieri; "** Martín J. Mazzoglio y Nabar \& ***Fabián A. Castro Barros

\begin{abstract}
ALGIERI, R. D.; MAZZOGLIO Y NABAR, M. J. \& CASTRO BARROS, F. A. Espacios virtuales de enseñanza y aprendizaje (EVEA) en esplacnología: Especificidades pedagógicas en su enseñanza topográfica. Int. J. Morphol., 30(3):908-915, 2012.

RESUMEN: La adherencia a espacios virtuales de enseñanza y aprendizaje (EVEA) y su utilidad en la enseñanza de la anatomía humana fue demostrada en estudios preliminares. El objetivo fue evaluar el rendimiento con un EVEA en la rotación de Esplacnología determinando las características pedagógicas en su enseñanza topográfica. Se realizó un estudio observacional, de tipo transversal, mediante el uso de un EVEA como un recurso pedagógico adicional a los trabajos prácticos (TP) de Esplacnología. Se implementó en 352 alumnos de la asignatura Anatomía, se valoró la adherencia y rendimiento obtenido con diferentes estrategias pedagógicas provistas en el EVEA y se aplicaron parámetros estadísticos a los resultados. Determinamos especificidades en el uso y las características laborales de los alumnos que influyeron en el rendimiento, obteniendo mejores resultados en los TP de abdomen (86,08\% de aprobados) y en actividades que incluyeron imágenes (TP aprobados $=81,32 \%$; TP aprobados con el $100 \%$ de respuestas correctas $=44,53 \%$ ). La cantidad de horas trabajadas semanales fue directamente proporcional al promedio de ingresos $(\mathrm{R} 2=0,82)$ e inversamente al tiempo promedio de logueo $(R 2=0,84)$. En nuestra cohorte objetivamos beneficios en el estudio de la Esplacnología con un espacio virtual de enseñanza y aprendizaje como recurso pedagógico adicional a los trabajos prácticos.
\end{abstract}

PALABRAS CLAVE: Espacio virtual de enseñanza y aprendizaje; Esplacnología; Pedagogía.

\section{INTRODUCCIÓN}

El uso de las nuevas tecnologías de la información influye en el conocimiento, las percepciones y las representaciones que tienen sus usuarios, en especial los jóvenes, no sólo en relación con el material de estudio sino también con sus compañeros y docentes (Popescu \& Navarro, 2005; Correa Gorospe, 2005; Montero O’farril, 2010). Estudios preliminares nos permitieron objetivar que la implementación de Espacios Virtuales de Enseñanza y Aprendizaje (EVEA) en la enseñanza de grado de la Anatomía Humana conlleva beneficios en el rendimiento de los educandos y genera un impacto en la adherencia con la materia (Algieri et al., 2008a, 2008b, 2009, 2011; Gazzotti et al., 2010, 2011).
Pudimos determinar que dicho impacto subjetivo está relacionado con el tiempo dedicado a la asignatura (el EVEA permite acomodarse a la disponibilidad horaria de los alumnos) (Algieri et al., 2008a, 2008b, 2009, 2011), con la concepción "integradora-educacional" de uso de los recursos virtuales (basándonos en el paradigma pedagógico donde los alumnos tienen un rol activo en su proceso de aprendizaje basado en la exploración y crítica del conocimiento) (Burgos \& Koper, 2005; Duart et al., 2003), con los nuevos enfoques visuoespaciales que permite el espacio virtual (imágenes bi y tridimensionales de material cadavérico y de estudios complementarios) (Algieri et al., 2008b), con la po-

\footnotetext{
* Médico, Universidad de Buenos Aires. Especialista en Cirugía General. Profesor Adjunto de Anatomía e Histología, UM. Jefe Trabajos Prácticos de Anatomía, III Cátedra de Anatomía, Universidad de Buenos Aires, Buenos Aires, Argentina.

** Médico, Universidad de Buenos Aires, Especialista en Psiquiatría. Jefe de Trabajos Prácticos de Anatomía, III Cátedra de Anatomía, Facultad de Medicina- Universidad de Buenos Aires. Docente Auxiliar de Farmacología y de Psiquiatría, Facultad de Medicina-UBA. Monitor en Investigaciones Clínicas y Farmacológicas, Facultad de Medicina, Universidad de Buenos Aires, Buenos Aires, Argentina.

**** Docente Auxiliar de Anatomía, Facultad de Medicina, Universidad de Buenos Aires, Buenos Aires, Argentina.
} 
sibilidad de intercambio de información bidireccional entre alumnos y entre éstos y los tutores (Lara \& Duart, 2005; Montero O’farril; Rubio, 2003), sin hallar relación con las diferencias socio-económicas de los usuarios ni la experiencia previa en e-learning (Algieri et al., 2008b; Lara \& Duart).

Este tipo de Tecnología de Información y Comunicación (TIC) es una herramienta polivalente que permite no sólo presentar imágenes y reconstrucciones en 3D, sino también presentar actividades en forma de casos clínicos simulando situaciones reales, actividades que inician la formación en competencias de los estudiantes y resignifican el proceso de enseñanza-aprendizaje mediante la reelaboración subjetiva del contenido por parte de los alumnos en función de su estructura cognitiva.

El objetivo del presente trabajo es evaluar la utilidad de un EVEA como recurso pedagógico en la rotación de Esplacnología con especificación de la anatomía topográfica estudiada. Asimismo, evaluar la implicancia subjetiva de los participantes con el recurso pedagógico en función de sus características socioeconómicas.

\section{MATERIAL Y MÉTODO}

Se realizó un estudio observacional de tipo transversal mediante el diseño un EVEA con el programa Moodle $₫$ que fue implementado como un recurso instruccional complementario a los trabajos prácticos con material cadavérico y a las clases teóricas brindadas por docentes de la Cáte- dra e incluyó actividades varias: casos clínico-quirúrgicos, correlatos de imágenes estructurales con preparados anatómicos y casos de imagenología con reconstrucciones en 3D.

La población interviniente estuvo representada por 352 alumnos de 3 comisiones del año 2011 correspondientes a la cursada de Anatomía de la $3^{\circ}$ Cátedra de Anatomía de la Facultad de Medicina de la Universidad de Buenos Aires. Las características poblacionales de la muestra se exhiben en la Tabla I.

Los datos utilizados de los alumnos logueados fueron obtenidos directamente de las estadísticas que el programa Moodle ${ }^{\circledR}$ provee de los trabajos prácticos correspondientes a la rotación de Esplacnología. Se dividieron los trabajos prácticos según la anatomía topográfica a la que pertenecían: 4 trabajos prácticos correspondían a la zona topográfica del cuello, 3 a la del tórax, 4 al abdomen y 3 a la pelvis. Fueron excluidos los registros de ingresos durante la semana de repaso previa al parcial de la rotación de esplacnología en que los alumnos vuelven a tener acceso a todos los TP. Para cada zona topográfica se extrajeron los resultados de cada alumno mediante el promedio aplicado a los datos de los parámetros evaluados en cada trabajo práctico correspondiente a la zona en cuestión. Los resultados fueron sometidos a pruebas de estadística descriptiva (promedio, máximo, mínimo) e inferencial (correlación r y R2) y se realizaron los gráficos mediante la utilización del Microsoft Excel@ 2007 para Windows. El presente trabajo de investigación se realizó atento a los reparos éticos y normativos vigentes (requisitos de las Good Clinical Practices -GCP-, disposiciones regulatorias y adhesión a principios éticos con origen en la Declaración de Helsinski).

Tabla I. Características poblacionales de la muestra.

\begin{tabular}{lcc}
\hline \multirow{2}{*}{ Sexo } & Masculino & $34,94 \%$ \\
& Femenino & $65,06 \%$ \\
& $18-22$ & $69,03 \%$ \\
Edad & $23-27$ & $26,99 \%$ \\
& $28-32$ & $2,84 \%$ \\
& $33-42$ & $0,85 \%$ \\
Trabaja & $43-52$ & $0,28 \%$ \\
& $\mathrm{Si}$ & $38,47 \%$ \\
Horas de trabajo en la semana & $\mathrm{No}$ & $49,53 \%$ \\
& $>30 \mathrm{Hr} / \mathrm{Semana}$ & $36,10 \%$ \\
¿Tiene como alumno alguna experiencia previa en el uso de e-learning? & $14,52 \%$ \\
\end{tabular}




\section{RESULTADOS}

En los parámetros de uso objetivamos que en los TP de tórax el 60,8\% (n=214) de los alumnos tuvo 1-2 veces de ingreso por semana en promedio en contraste con los 4-5 veces/semana de los TP de abdomen $(51,70 \%$; $\mathrm{n}=182)$ y cuello $(44,60 \% ; n=157)$. El mayor promedio de cantidad de ingresos por día fue de 1-3 veces en los prácticos de abdomen $(69,03 \%)$, mientras que el menor fue en tórax. El momento de mayor frecuencia de ingreso al espacio virtual en relación con el TP semanal correspondió al mismo día del TP para los prácticos de abdomen (69,32\% de los alumnos), mientras el $61.08 \%$ de los alumnos ingresó luego de las 72 horas de cursados los TP de tórax (Fig. 1).
El mayor tiempo promedio de permanencia en el EVEA fue entre 60 y 120 minutos para los prácticos de cuello, abdomen y pelvis; mientras que en los de tórax registramos que el $48,01 \%$ de los alumnos permanecieron logueados entre 20 y 40 minutos. La banda horaria con mayor frecuencia de ingreso fue entre las 20 y 24 horas para todos los TP sin especificación de la anatomía topográfica de los TP (Fig. 2).

En las preguntas para evaluar la adherencia subjetiva de los alumnos al EVEA pudimos determinar que los TP referentes a la anatomía del cuello y del abdomen fueron los que obtuvieron mejores índices, en contraste con los TP del tórax. Los encuestados destacaron la utilidad del intercambio entre alumnos mediante el espacio virtual, del material adjunto como complemento de los TP, de la correlación en-

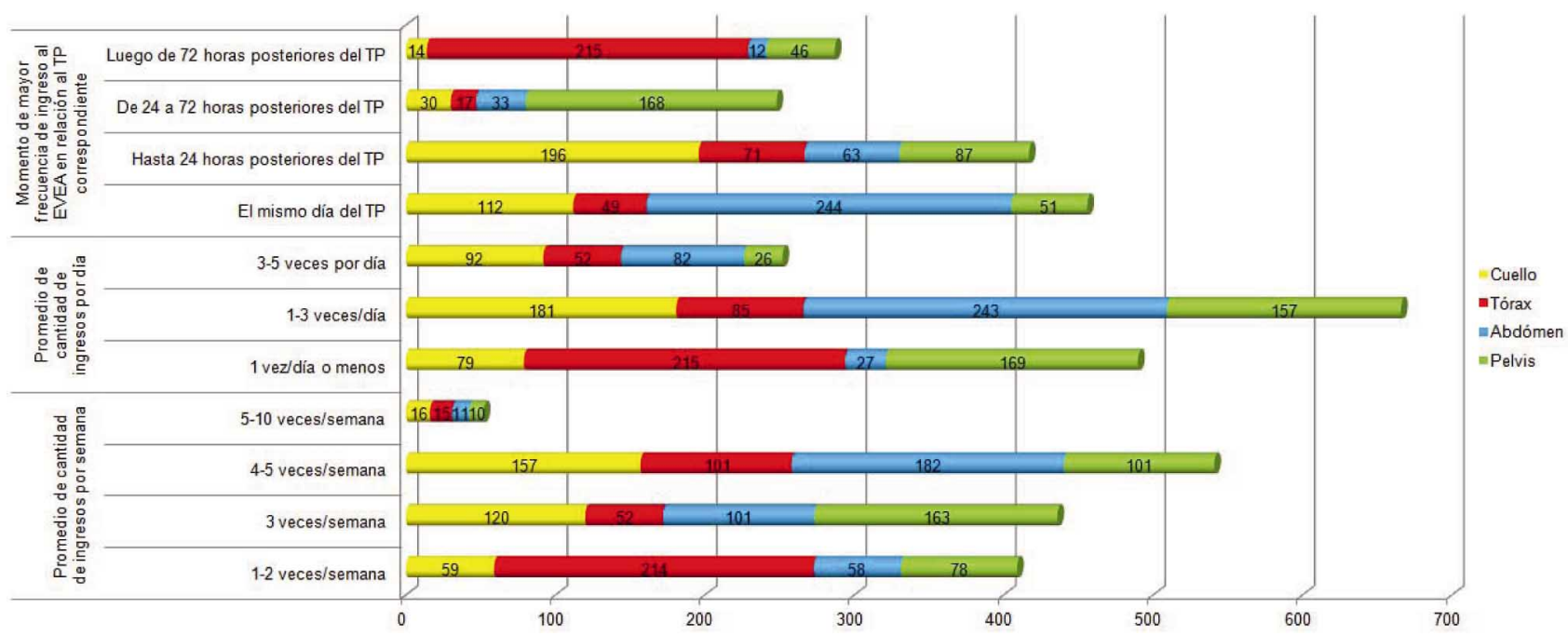

Fig. 1. Cantidad de respuestas a 3 parámetros evaluados sobre datos de uso del EVEA en función de la anatomía topográfica de los TP de esplacnología.

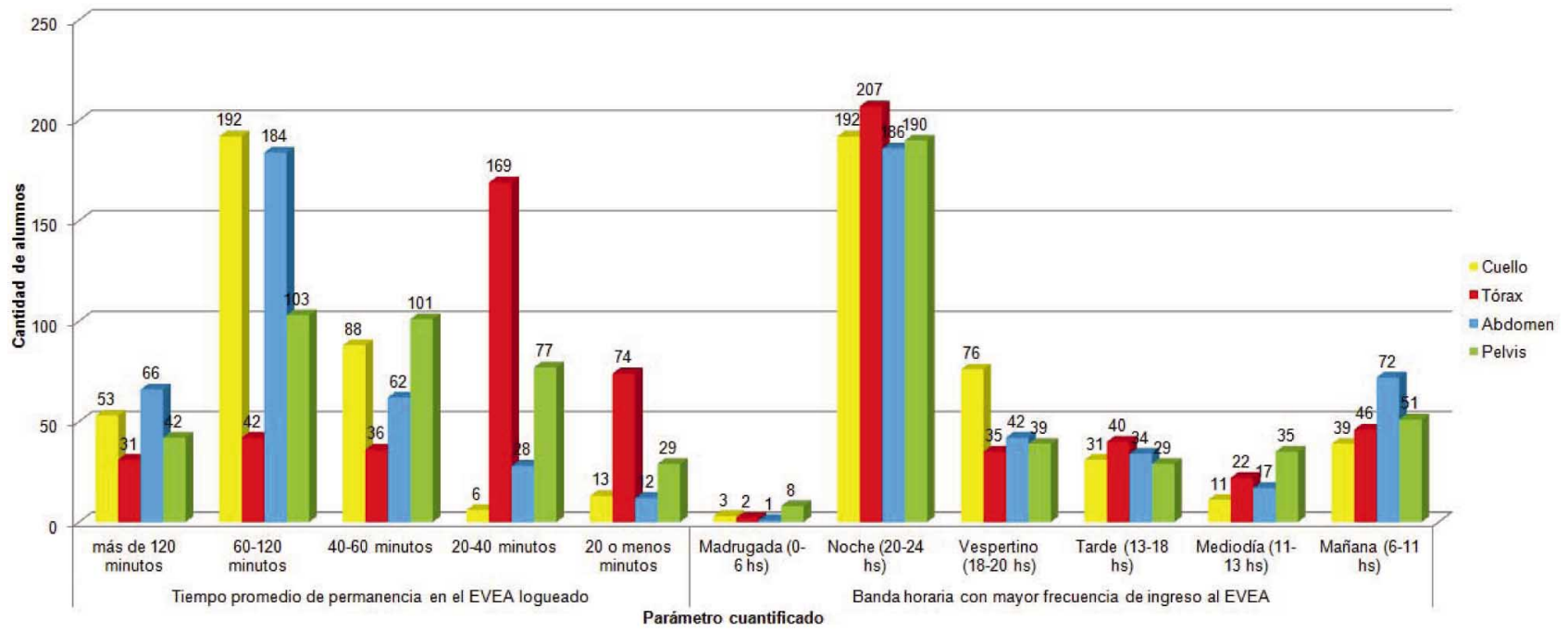

Fig. 2. Cantidad de respuestas a 2 parámetros evaluados sobre datos de uso del EVEA en función de la anatomía topográfica de los TP de esplacnología. 


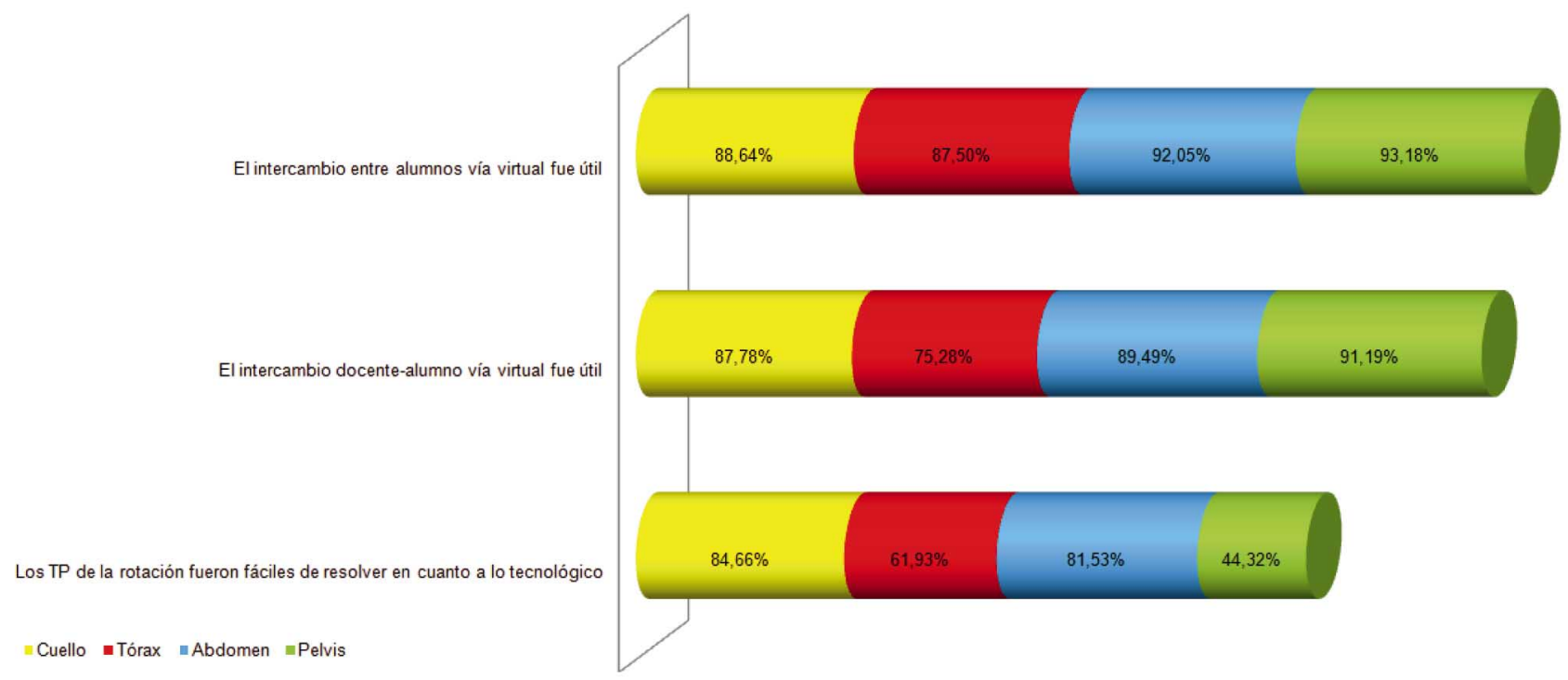

Fig. 3. Porcentaje de respuestas sobre 3 preguntas relacionadas con la adherencia subjetiva de los alumnos en función de la anatomía topográfica de los TP de esplacnología.

El conocimiento de la Anatomía Normal me sivió para comprender los estudios de imágenes

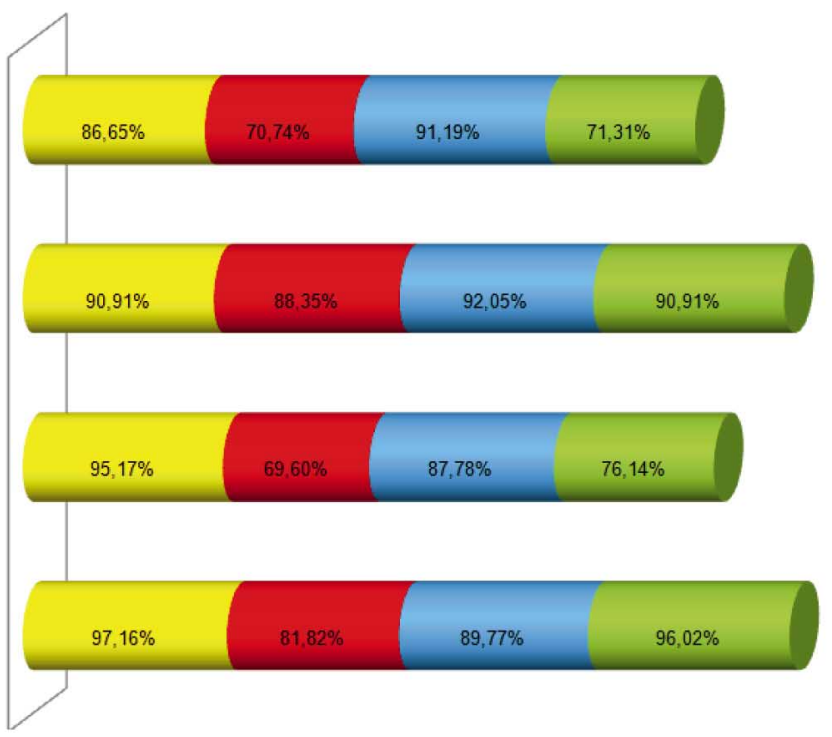

" Cuello $\|$ Tórax $\|$ Abdomen $=$ Pelvis

Fig. 4. Porcentaje de respuestas sobre 4 preguntas relacionadas con la adherencia subjetiva de los alumnos en función de la anatomía topográfica de los TP de esplacnología.

tre los ejercicios con los conceptos abordados en las clases teóricas (Figs. 3, 4 y 6). Asimismo, en todos los prácticos los alumnos destacaron que los ejercicios referentes a correlatos de imágenes estructurales con los preparados anatómicos y los casos de imágenes con reconstrucciones en 3D fueron los de mayor utilidad para su proceso de aprendizaje (Figs. 5 y 6).

En relación con el rendimiento de los alumnos en los TP, sin especificación de la estrategia pedagógica uti- lizada, los correspondientes a la anatomía topográfica del abdomen fueron los que obtuvieron mejores puntajes y porcentaje de aprobados $(86,08 \%)$, seguidos por los de cuello $(83,81 \%)$, pelvis $(66,57 \%)$ y tórax $(56,44 \%)$. También en los TP de abdomen registramos el mayor porcentaje de alumnos con el $100 \%$ de respuestas correctas $(58,14 \%)$, seguidos por los de pelvis $(44,60 \%)$, cuello $(36,55 \%)$ y tórax $(12,41 \%)$. Determinamos que en los TP de tórax los alumnos alcanzaron el mayor porcentaje de desaprobados $(43,56 \%)$ (Fig. 7). 


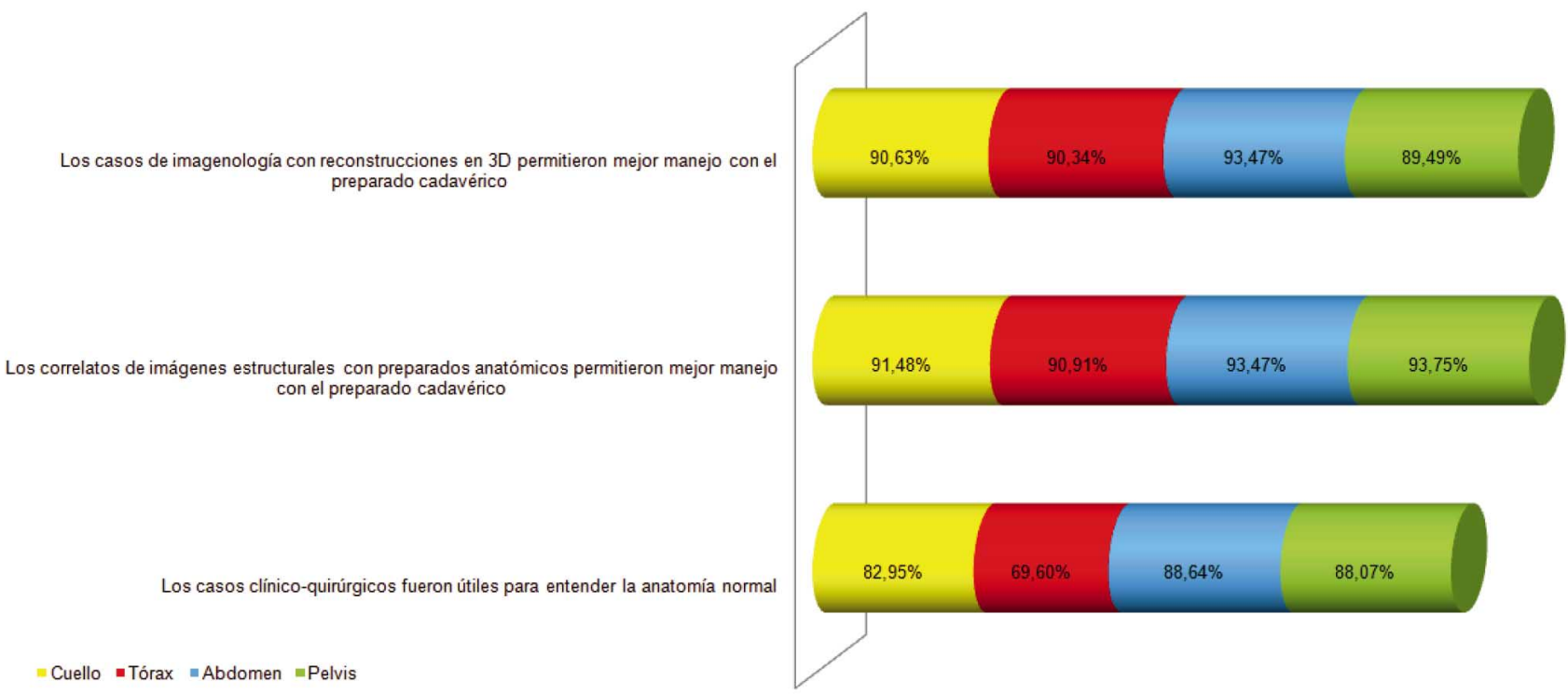

Fig. 5. Porcentaje de respuestas sobre 3 preguntas relacionadas con la adherencia subjetiva de los alumnos en función de la anatomía topográfica de los TP de esplacnología.

Los casos de imagenología con reconstrucciones en 3D permitieron mejor manejo con el preparado cadavérico

Los correlatos de imágenes estructurales con preparados anatómicos permitieron mejor manejo con el preparado cadavérico

Los casos clínico-quirúrgicos fueron útiles para entender la anatomía normal

El conocimiento de la Anatomía Normal me sirvió para comprender los estudios de imágenes

El material y los ejercicios de la rotación tuvieron correlación con los conceptos de las clases teóricas

El material y los ejercicios de la rotación tuvieron correlación con los conceptos de las clases prácticas con cadáveres

Los ejercicios y el material adjunto fueron útiles para complementar los TP de la rotación

El intercambio entre alumnos vía virtual fue útil

El intercambio docente-alumno vía virtual fue útil

Los TP de la rotación fueron fáciles de resolver en cuanto a lo tecnológico
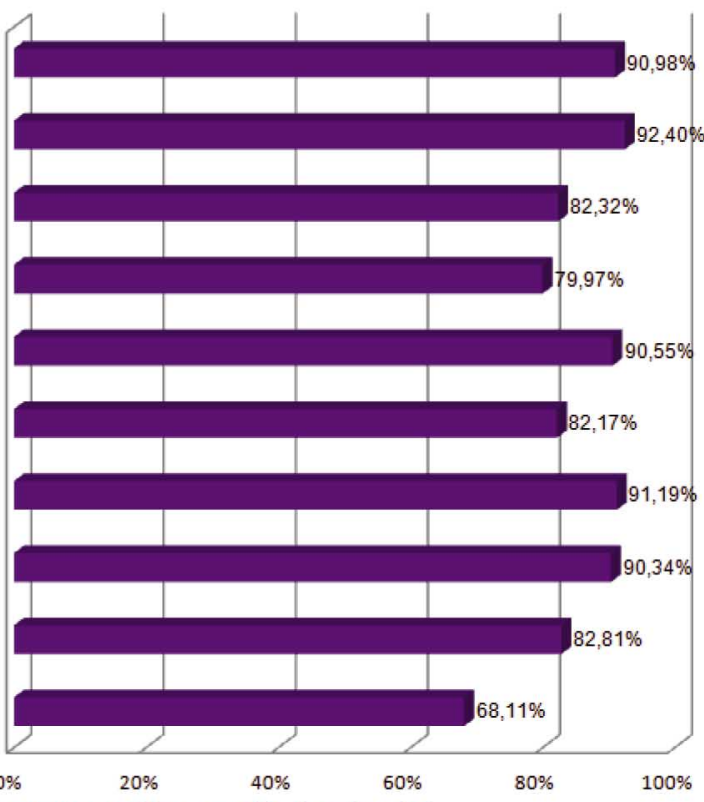

Promedio de respuesta positiva en rotación de esplacnología

Fig. 6. Porcentaje de respuestas sobre la adherencia subjetiva de los alumnos al EVEA.

En relación con las estrategias pedagógicas de los $\mathrm{TP}$, determinamos que los casos de imagenología con reconstrucción 3D obtuvieron la mayor cantidad de TP aprobados y de TP con el $100 \%$ de respuestas correctas $(81,32 \%$; $44,53 \%)$, en particular los referentes al abdomen $(89,49 \%$; $70,45 \%)$. Los casos clínico-quirúrgicos presentaron el más alto nivel de TP desaprobados $(34,14 \%)$, en especial los referentes al tórax y pelvis (>50\%) (Figs. 8 y 9).
Determinamos que la cantidad de horas trabajadas semanales fue directamente proporcional al promedio de ingresos por semana al EVEA $(\mathrm{R} 2=0,82)$ e inversamente proporcional al tiempo promedio de permanencia en el espacio virtual $(\mathrm{R} 2=0,84)$ (Fig. 10). El rendimiento promedio de cada alumno en los TP de casos clínico-quirúrgicos presentó una correlación negativa con la cantidad de horas trabajadas semanales $(\mathrm{R} 2=0,77)$, destacándose en los TP de 


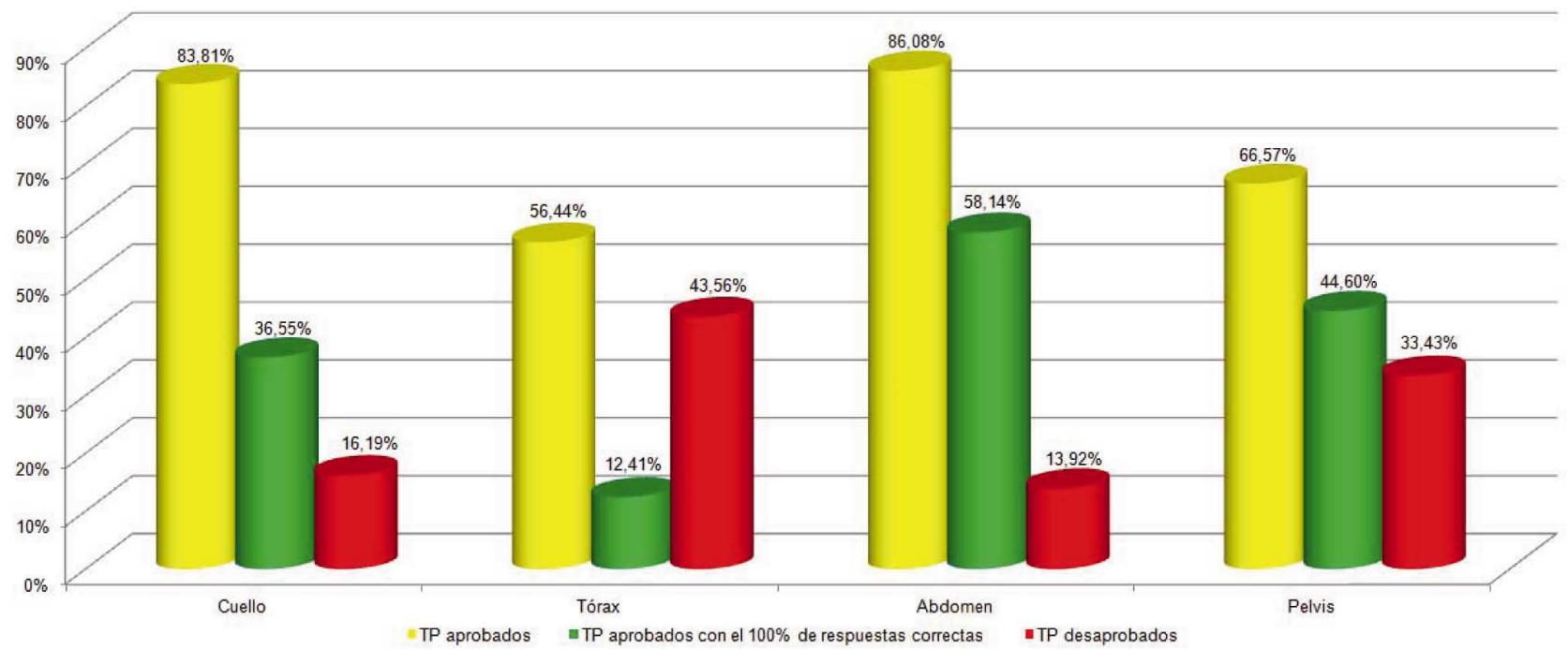

Fig. 7. Rendimiento de los alumnos en los ejercicios en función de la anatomía topográfica de los TP de esplacnología.

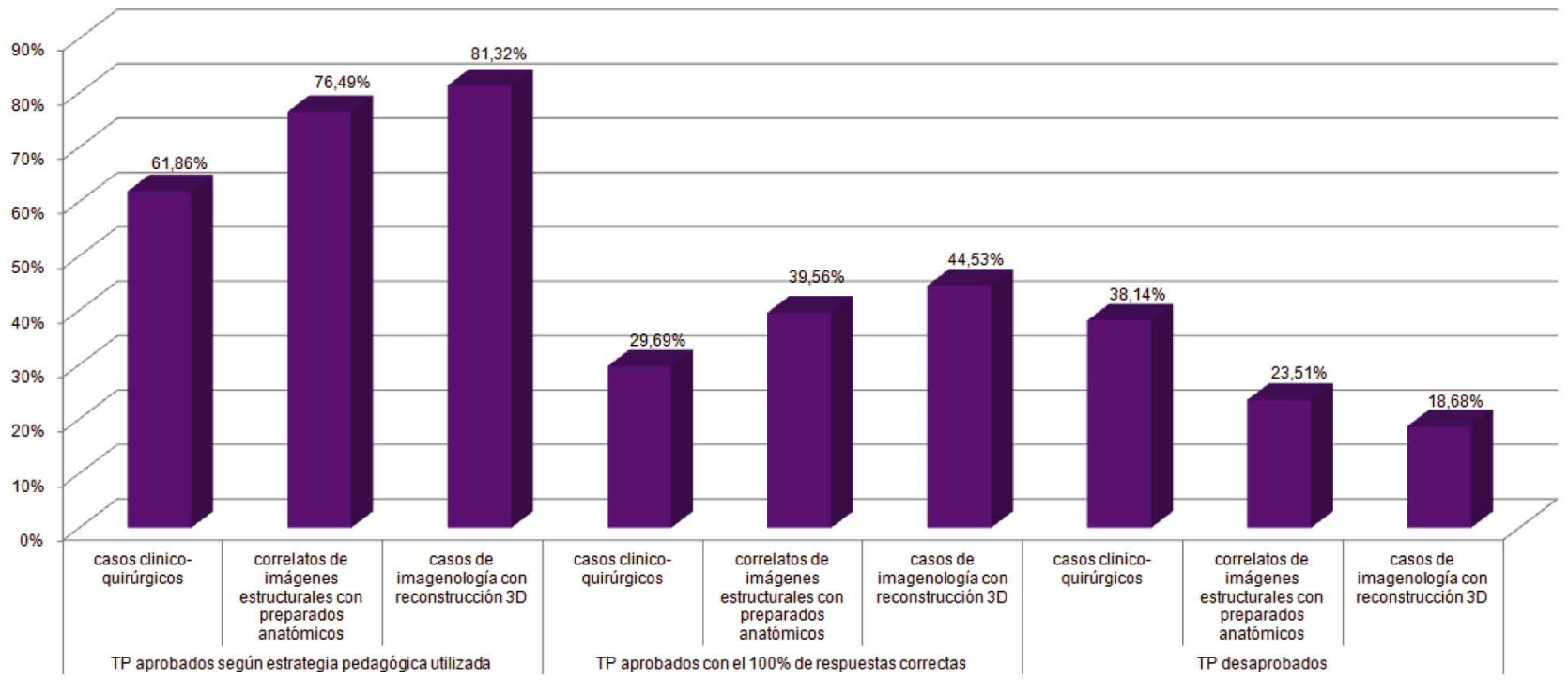

Fig. 8. Rendimiento de los alumnos en los ejercicios en función de la estrategia pedagógica de los mismos.

tórax $(\mathrm{R} 2=0,91)$. No se hallaron otras correlaciones significativas entre las variables analizadas.

En conclusión, en la cohorte estudiada ratificamos la adherencia de los alumnos a este tipo de Tecnología de la Información y la Comunicación en la rotación de Esplacnología. Objetivamos especificidades pedagógicas en la anatomía topográfica estudiada relacionadas con el uso del espacio virtual y características laborales de los alumnos, que condicionaron el rendimiento en los trabajos prácticos. Los trabajos prácticos relacionados con imagenología, con especificación de los de abdomen, obtuvieron un mejor rendimiento en comparación con los casos clínico-quirúrgicos. 


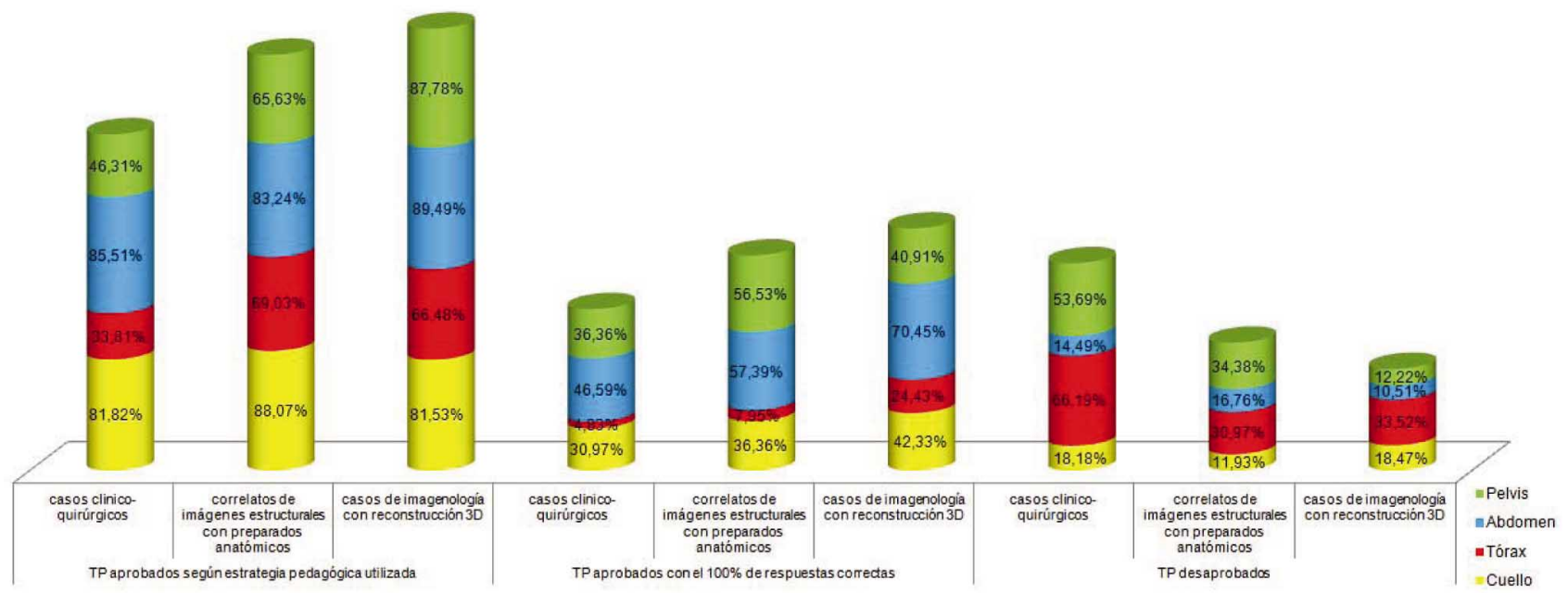

Fig. 9. Rendimiento de los alumnos en los ejercicios en función de la estrategia pedagógica de los mismos y de la anatomía topográfica de los TP de esplacnología.

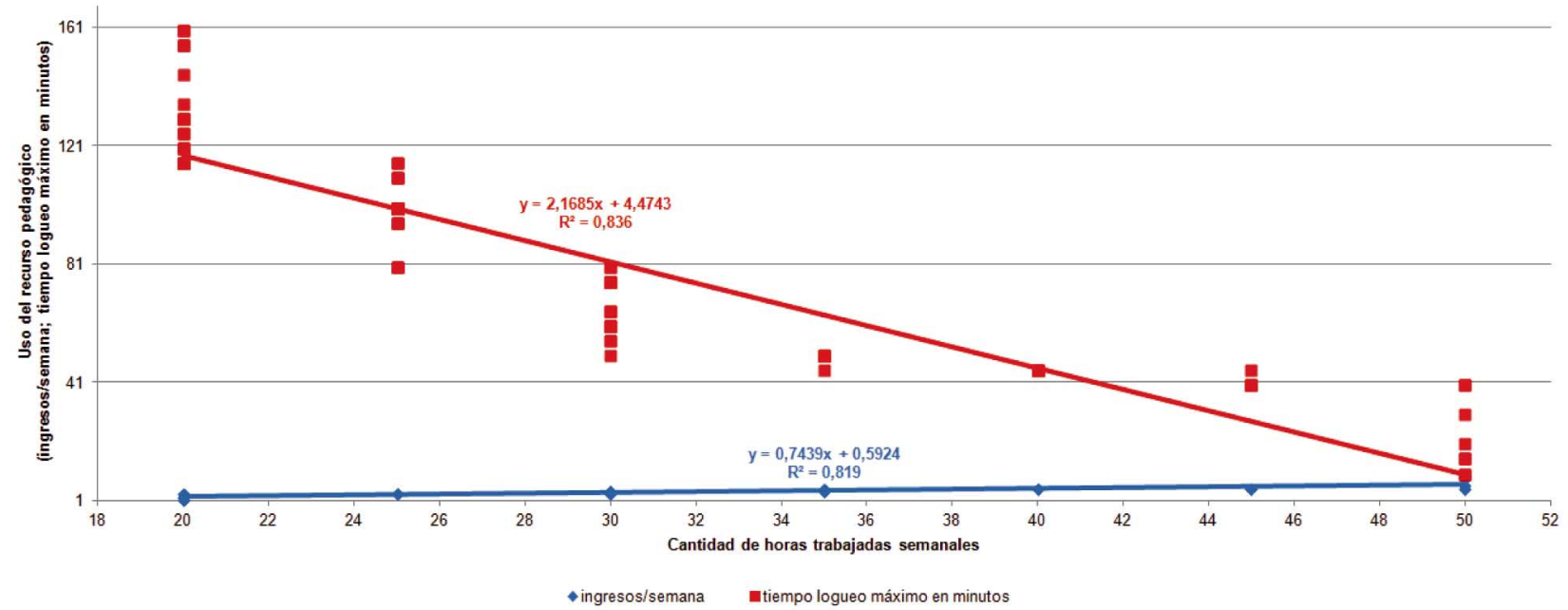

Fig. 10. Correlación entre la cantidad de horas de trabajo semanal de los alumnos y el uso del recurso pedagógico.

ALGIERI, R. D.; MAZZOGLIO Y NABAR, M. J. \& CASTRO BARROS, F. A. Virtual teaching and learning spaces (VTLS) in splanchnology: Pedagogical specificities in topographic teaching. Int. J. Morphol., 30(3):908-915, 2012.

SUMMARY: Adherence to virtual teaching and learning spaces (VTLS) and their usefulness when teaching human anatomy have been shown in preliminary studies. The aim was to evaluate performance with a VTLS on Splanchnology rotation by specifying the pedagogical characteristics of its topographic teaching. A cross-sectional observational study was conducted using a VTLS as a pedagogic resource additional to practical works (PW) on Splanchnology. It was implemented in 352 students from the Anatomy course; adherence and performance were assessed through different pedagogical strategies provided in the VTLS, and statistical standards were applied to results. We established specificities in the students' use and working characteristics influencing performance, and achieved better results in PW on the abdomen (86.08\% students passed) and image-including tasks (passed PW $=81.32 \%$; passed PW with $100 \%$ correct answers $=44.53 \%)$. The number of weekly hours devoted to work was directly proportional to the average number of logins (R2=0.82) and inversely proportional to average login time $(\mathrm{R} 2=0.84)$. Our cohort objectified benefits in the study of Splanchnology with a virtual teaching and learning space as a pedagogic resource additional to practical works.

KEY WORDS: Virtual teaching and learning space; Splanchnology; Pedagogy. 


\section{REFERENCIAS BIBLIOGRÁFICAS}

Algieri, R. D.; Ferrante, S. \& Mazzoglio y Nabar, M. J. Implementación de TIC en la enseñanza universitaria de la anatomía del hígado: aspectos neurobiológicos y psicopedagógicos, 2008a. Disponible en: www.diegolevis.com.ar/secciones/ Articulos/tic_medicina.pdf

Algieri, R. D.; Ferrante, M. S.; Nitto, D.; Verger, A.; Mazzoglio y Nabar, M. J. Rol de las Tecnologías Digitales para la enseñanza en cirugía. $79^{\circ}$ Congreso Argentino de Cirugía, 2008b.

Algieri, R. D.; Mazzoglio y Nabar, M.J.; Dogliotti, C.G. \& Gazzotti, A. TICs aplicadas a la enseñanza del aparato digestivo. Int. J. Morphol., 27(4):1261-8, 2009.

Algieri, R. D.; Mazzoglio y Nabar, M. J.; Dogliotti, C. G.; Rey, L.; Gómez, A. \& Tornese, E. B. Espacio Virtual de Enseñanza y Aprendizaje aplicado en la enseñanza del Tórax: adherencia y utilidad didáctica. Rev. Hosp. Aeronaútico Central, 7(2):37-9, 2011.

Burgos, D. \& Koper, R. Comunidades virtuales, grupos y proyectos de investigación sobre IMS Learning Design. Status quo, factores clave y retos inmediatos. RELIEVE, 11(2):189-200, 2005.

Correa Gorospe, J. M. La integración de plataformas de e-learning en la docencia universitaria: Enseñanza, aprendizaje e investigación con Moodle en la formación inicial del profesorado. Rev. Latinoam. Tecnol. Educ., 4(1):37-48, 2005.

Duart, J. M.; Lara, P. \& Saigí, F. Gestión de contenidos en el diseño de contenidos educativos. UOC, 2003. Disponible en línea: http:/ /www.uoc.edu/dt/20237/index.html

Gazzotti, A. M.; Algieri, R. D.; Dogliotti, C. G.; Mazzoglioy Nabar, M. J.; Rey, L.; Jiménez Villarruel, H. N.; Gómez, A.; Pró, E. A. Adhesión al Espacio Virtual de Enseñanza y Aprendizaje (Moodle) en Alumnos de Anatomía. Rev. Arg. Anat. Online, 2(2):60-3, 2011.

Gazzotti, A.; Rey, L.; Jiménez Villarruel, H. N.; Mazzoglio y Nabar, M. J. \& Gómez, A. Comparación del rendimiento de los alumnos en evaluación parcial con uso de campus virtual (Moodle) como recurso. XLVII Congreso Argentino de Anatomía, 2010.

Lara, P. \& Duart, J. M. Gestión de contenidos en el e-learning: acceso y uso de objetos de información como recurso estratégico. Rev. Univ. Soc. Conoc., 2(2):6-14, 2005.

Montero O'farrill, J. L. Estrategia para la introducción de las Tecnologías de la Información y las Comunicaciones. Rev. Latinoam. Tecnol. Educ., 9(1):75-87, 2010.

Popescu B. M. \& Navarro, V. Comparación del aprendizaje en internet con la clase convencional en estudiantes de medicina en Argentina. Educ. Med., 8(4):204-7, 2005.
Rubio, M. J. Enfoques y modelos de evaluación del e-learning. RELIEVE, 9(2):101-20, 2003.

\author{
Dirección para correspondencia: \\ Rubén Daniel Algieri \\ Especialista en Cirugía General \\ Profesor Adjunto de Anatomía e Histología, UM. \\ Jefe Trabajos Prácticos de Anatomía \\ III Cátedra de Anatomía \\ Universidad de Buenos Aires \\ Buenos Aires \\ ARGENTINA
}

Email: rdalgieri08@hotmail.com

Recibido : 05-05-2012

Aceptado: 13-06-2012 